\title{
Automated CT Perfusion for Ischemic Core Volume Prediction in Tandem Anterior Circulation Occlusions
}

\author{
Diogo C. Haussen Seena Dehkharghani Mikayel Grigoryan \\ Meredith Bowen Leticia C. Rebello Raul G. Nogueira \\ Emory University and Grady Memorial Hospital, Atlanta, Ga., USA
}

\section{Key Words}

Ischemic stroke · Endovascular treatment · Perfusion imaging · Computed tomography

\begin{abstract}
Background/Aim: CT perfusion (CTP) predicts ischemic core volumes in acute ischemic stroke (AIS); however, assumptions made within the pharmacokinetic model may engender errors by the presence of tracer delay or dispersion. We aimed to evaluate the impact of hemodynamic disturbance due to extracranial anterior circulation occlusions upon the accuracy of ischemic core volume estimation with an automated perfusion analysis tool (RAPID) among AIS patients with large-vessel occlusions. Methods: A prospectively collected, interventional database was retrospectively reviewed for all cases of endovascular treatment of AIS between September 2010 and March 2015 for patients with anterior circulation occlusions with baseline CTP and full reperfusion (mTICI3). Results: Out of 685 treated patients, 114 fit the inclusion criteria. Comparison between tandem $(n=21)$ and nontandem groups $(n=93)$ revealed similar baseline ischemic core (20 \pm 19 vs. $\left.19 \pm 25 \mathrm{~cm}^{3} ; p=0.8\right), T_{\max }>6 \mathrm{~s}(175 \pm 109$ vs. $162 \pm$ $\left.118 \mathrm{~cm}^{3} ; p=0.6\right), T_{\max }>10 \mathrm{~s}\left(90 \pm 84\right.$ vs. $\left.90 \pm 91 \mathrm{~cm}^{3} ; p=0.9\right)$, and final infarct volumes (45 \pm 47 vs. $37 \pm 45 \mathrm{~cm}^{3} ; p=0.5$ ). Baseline core volumes were found to correlate with final infarct volumes for the tandem $(r=0.49 ; p=0.02)$ and nontandem $(r=0.44 ; p<0.01)$ groups. The mean absolute difference between estimated core and final infarct volume was similar between patients with and those without $\left(24 \pm 41 \mathrm{vs} .17 \pm 41 \mathrm{~cm}^{3} ; \mathrm{p}=0.5\right)$ tandem lesions. Conclusions: The prediction of baseline ischemic core volumes through an optimized CTP analysis employing rigorous normalization, thresholding, and voxel-wise analysis is not significantly influenced by the presence of underlying extracranial carotid steno-occlusive disease in large-vessel AIS.




\section{Introduction}

Endovascular treatment of large-vessel acute ischemic stroke (AIS) has recently been demonstrated to be effective [1-5]. Although the most appropriate selection method for AIS thrombectomy remains elusive, the use of an automated CT perfusion (CTP) system (RAPID; iSchemaView, Inc., Menlo Park, Calif., USA) has been demonstrated to provide rapid and accurate prediction of core stroke volumes $[6,7]$. However, vulnerabilities inherent in the pharmacokinetic models in widespread use, particularly those related to delay/dispersion of the bolus in the tissue or arterial input, have been discussed extensively [8-10]. The potential for delay-corrected perfusion quantitation was recently reported for limited software environments in a digital phantom; however, the potential impact of complex hemodynamic disturbances in clinical imaging, as may occur with proximal tandem stenoses, remains uncertain [11].

With the aforementioned in mind, we undertook a retrospective analysis of an AIS cohort with tandem steno-occlusive disease, hypothesizing robust ischemic core and penumbra predictions despite the potential delay and dispersion effects known to complicate dynamic bolus passage methodologies. We aimed to evaluate the potential differences in core and penumbral measures as related to the presence of tandem cerebrovascular disease, hypothesizing a robust prediction of the tissue state when using appropriately delay-corrected perfusion processing. This analysis was undertaken using the clinical implementation of the fully automated software suite for the estimation of ischemic core volume in patients with underlying ipsilateral extracranial steno-occlusive carotid artery disease undergoing successful thrombectomy.

\section{Methods}

The prospectively collected interventional database from a tertiary care academic institution for consecutive cases of endovascular AIS treatment between September 2010 and March 2015 was reviewed, with (a) anterior circulation large-vessel occlusions that (b) underwent pretreatment CTP and (c) achieved full reperfusion [mTICI3 (modified treatment in cerebral ischemia)] [12]. This study was approved by the local Institutional Review Board.

\section{Imaging}

CTP was evaluated with a fully automated, commercially available software environment (RAPID version 4.5.0). Details of the analytic pipeline have previously been discussed [13]. Briefly, 2 contiguous CTP slabs were obtained for 8-cm combined coverage of the supratentorial brain, obtained at eight 5-mm slices per slab. Cine mode acquisition $(80 \mathrm{kV}, 100$ auto-mA), permitting high-temporal-resolution (60-second sampling window and continuous 1-second sampling interval) dynamic bolus passage imaging, was obtained following the administration of iodinated contrast. The total hypoperfused volume was defined by a $>6$-second delay for the maximum of the tissue residue function $\left(\mathrm{T}_{\max }>6 \mathrm{~s}\right)$. The ischemic core lesion was defined by a cerebral blood flow (CBF) reduction to $<30 \%$ of the corresponding contralateral territory. The target mismatch profile was defined as a core $\leq 50 \mathrm{~cm}^{3}$, absolute mismatch $\geq 15 \mathrm{~cm}^{3}, \mathrm{~T}_{\max }>10 \mathrm{~s} \leq 100 \mathrm{~cm}^{3}$, and the mismatch ratio $>1.8$, with processed parametric maps overlaid upon the source CTP data for review purposes [7]. Nondiagnostic RAPID scans $(n=14)$ and cases with technically inadequate follow-up scans $(n=5)$ were excluded. Extracranial carotid artery occlusive disease was defined as per the presence of occlusion/nearocclusion on conventional angiography [14].

Follow-up in all patients included MRI documenting final infarct volumes before hospital discharge. Final infarct volumes were defined preferentially and predominantly by MRI. Noncontrast CT was performed if contraindications precluded MRI (e.g., with a pacemaker or clinical instability). All follow-up studies were performed within the first 5 days of treatment. DWI was preferentially used in final infarction volume estimates when MRI was obtained within $72 \mathrm{~h}$ of the stroke, and T2-FLAIR images were used thereafter to avoid confounding effects of early pseudonormalization. For noncontrast CT, window/level settings were adjusted 


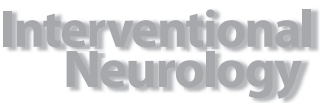

Table 1. Univariate analysis comparing patients with and without tandem occlusions

\begin{tabular}{l|l}
\hline Intervent Neurol 2016:5:81-88 \\
\hline DOI: 10.1159/000445763 & $\begin{array}{l}\text { @ 2016 S. Karger AG, Basel } \\
\text { www.karger.com/ine }\end{array}$ \\
\hline
\end{tabular}

Haussen et al.: Automated CT Perfusion for Ischemic Core Volume Prediction in Tandem Anterior Circulation Occlusions

\begin{tabular}{|c|c|c|c|}
\hline & $\begin{array}{l}\text { Tandem } \\
(\mathrm{n}=21)\end{array}$ & $\begin{array}{l}\text { Nontandem } \\
(\mathrm{n}=93)\end{array}$ & $\mathrm{p}$ value \\
\hline \multicolumn{4}{|l|}{ Baseline } \\
\hline Age, years & $60.2 \pm 16.5$ & $64.2 \pm 15.6$ & 0.34 \\
\hline Gender (male) & $14(66 \%)$ & $46(49 \%)$ & 0.22 \\
\hline Hypertension & $11(52 \%)$ & $70(75 \%)$ & 0.06 \\
\hline Dyslipidemia & $11(52 \%)$ & $32(34 \%)$ & 0.14 \\
\hline Atrial fibrillation & $4(19 \%)$ & $40(43 \%)$ & 0.03 \\
\hline Diabetes & $2(9 \%)$ & $18(19 \%)$ & 0.28 \\
\hline Smoking & $5(24 \%)$ & $9(9 \%)$ & 0.13 \\
\hline Intravenous tPA & $11(52 \%)$ & $43(46 \%)$ & 0.80 \\
\hline NIHSS score & $15.8 \pm 4.9$ & $18.7 \pm 5.6$ & 0.01 \\
\hline Systolic blood pressure, $\mathrm{mm} \mathrm{Hg}$ & $127 \pm 37$ & $122 \pm 38$ & 0.60 \\
\hline NCCT ASPECTS score & $7.1 \pm 1.8$ & $7.9 \pm 1.6$ & 0.11 \\
\hline \multicolumn{4}{|l|}{ Intracranial occlusion site ${ }^{a}$} \\
\hline ICA-T & $6(33 \%)$ & $12(13 \%)$ & 0.09 \\
\hline MCA-M1 & $9(50 \%)$ & $59(63 \%)$ & 0.09 \\
\hline MCA-M2 & $3(16 \%)$ & $22(23 \%)$ & 0.34 \\
\hline \multicolumn{4}{|l|}{ Procedure } \\
\hline General anesthesia & $4(19 \%)$ & $17(18 \%)$ & 0.95 \\
\hline Last normal to groin puncture, $\mathrm{h}$ & $7.0 \pm 3.3$ & $7.0 \pm 5.5$ & 0.98 \\
\hline CTP to end of procedure, $\mathrm{h}$ & $2.3 \pm 0.7$ & $2.0 \pm 0.8$ & 0.10 \\
\hline Procedural length, $\mathrm{h}$ & $1.6 \pm 0.7$ & $0.9 \pm 0.6$ & $<0.01$ \\
\hline Stent retriever & $16(76 \%)$ & $80(86 \%)$ & 0.31 \\
\hline Full reperfusion & $21(100 \%)$ & $93(100 \%)$ & 1.00 \\
\hline \multicolumn{4}{|l|}{ Outcomes } \\
\hline \multicolumn{4}{|l|}{ Hemorrhage } \\
\hline PH-1 & $2(9 \%)$ & $5(5 \%)$ & 0.47 \\
\hline PH-2 & $0(0 \%)$ & $4(4 \%)$ & 0.33 \\
\hline SAH & $1(4 \%)$ & $2(2 \%)$ & 0.50 \\
\hline mRS score $0-2$ at 90 days & $14(66 \%)$ & $45(48 \%)$ & 0.19 \\
\hline \multicolumn{4}{|c|}{$\begin{array}{l}\text { NCCT ASPECTS = Noncontrast CT Alberta Stroke Program Early CT } \\
\text { Scan; ICA-T = internal carotid artery terminus; MCA = middle cerebral } \\
\text { artery; Last normal to groin puncture = time from last seen normal to } \\
\text { groin puncture; CTP to end of procedure = time from CTP completion } \\
\text { to end of procedure; PH = parenchymal hemorrhage; SAH = subarachnoid } \\
\text { hemorrhage; mRS = modified Rankin Scale. } \\
\quad{ }^{a} \mathrm{n}=18 / 21 \text { ( } 3 \text { patients had isolated cervical occlusions). }\end{array}$} \\
\hline
\end{tabular}


Haussen et al.: Automated CT Perfusion for Ischemic Core Volume Prediction in Tandem Anterior Circulation Occlusions

Table 2. Comparison of baseline RAPID CTP prediction and final infarct volumes

\begin{tabular}{|c|c|c|c|}
\hline Parameter & $\begin{array}{l}\text { Tandem } \\
(\mathrm{n}=21)\end{array}$ & $\begin{array}{l}\text { Nontandem } \\
(n=93)\end{array}$ & $\mathrm{p}$ value \\
\hline CBF core, $\mathrm{cm}^{3}$ & $20.8 \pm 19.3$ & $19.7 \pm 25.5$ & 0.83 \\
\hline $\mathrm{T}_{\max }>6 \mathrm{~s}, \mathrm{~cm}^{3}$ & $175.2 \pm 109.5$ & $162.1 \pm 118.1$ & 0.62 \\
\hline $\mathrm{T}_{\max }>10 \mathrm{~s}, \mathrm{~cm}^{3}$ & $90.3 \pm 84.7$ & $90.9 \pm 91.8$ & 0.97 \\
\hline Core $\leq 50 \mathrm{~cm}^{3}$ & $20(95 \%)$ & $84(90 \%)$ & 0.47 \\
\hline $\mathrm{T}_{\max }>10 \mathrm{~s} \leq 100 \mathrm{~cm}^{3}$ & $14(66 \%)$ & $65(70 \%)$ & 0.79 \\
\hline Absolute mismatch $\geq 15 \mathrm{~cm}^{3}$ & $20(95 \%)$ & $91(98 \%)$ & 0.50 \\
\hline Mismatch ratio $>1.8$ & $20(95 \%)$ & $91(98 \%)$ & 0.50 \\
\hline Target mismatch profile & $13(62 \%)$ & $61(65 \%)$ & 0.80 \\
\hline Final infarct volume ${ }^{\mathrm{a}}, \mathrm{cm}^{3}$ & $45.0 \pm 47.1$ & $37.5 \pm 45.6$ & 0.51 \\
\hline Difference predicted to final infarct volume ${ }^{\mathrm{b}}, \mathrm{cm}^{3}$ & $24.2 \pm 41.2$ & $17.8 \pm 41.3$ & 0.52 \\
\hline
\end{tabular}

a Determined by MRI $\leq 5$ days in $90 \%$. ${ }^{\text {b }}$ Mean absolute difference between estimated ischemic core and final infarct volume.

\section{Results}

Out of 685 patients treated within the study period, 114 patients fit the inclusion criteria and were included in the analysis. Twenty-one patients (18\%) had underlying extracranial carotid steno-occlusive disease, while 93 (82\%) had isolated intracranial large-vessel occlusions. The carotid disease etiology was mostly atherosclerotic $(n=16)$, while in the remaining cases it was related to dissections $(n=4)$ or Takayasu's arteritis $(n=1)$.

The baseline characteristics, procedural variables, and clinical outcomes of the patients with and those without tandem disease are displayed in table 1. Multivariate analysis only revealed lower initial National Institutes of Health Stroke Scale (NIHSS) scores (OR 0.86; 95\% CI 0.76-0.98; $p=0.03$ ) and longer procedural length (OR 1.01; 95\% CI 1.01-1.04; $p \leq 0.01$ ) to be independently associated with tandem disease as compared to patients with isolated intracranial occlusions.

The comparison between the tandem and the nontandem group revealed similar baseline ischemic core ( $20 \pm 19$ vs. $\left.19 \pm 25 \mathrm{~cm}^{3} ; \mathrm{p}=0.8\right), \mathrm{T}_{\max }>6 \mathrm{~s}(175 \pm 109$ vs. $162 \pm 118$ $\left.\mathrm{cm}^{3} ; \mathrm{p}=0.6\right), \mathrm{T}_{\max }>10 \mathrm{~s}\left(90 \pm 84 \mathrm{vs} .90 \pm 91 \mathrm{~cm}^{3} ; \mathrm{p}=0.9\right)$, and final infarct volumes $(45 \pm 47$ vs. $37 \pm 45 \mathrm{~cm}^{3} ; \mathrm{p}=0.5$ ) (table 2 ). The presence of a target mismatch profile (and each subcomponent) was similar between the groups. The baseline CTP core volumes were found to correlate statistically significantly with final infarct volumes for the tandem (fig. 1a; $\mathrm{r}=$ $0.49 ; \mathrm{p}=0.02$ ) and nontandem (fig. $1 \mathrm{~b} ; \mathrm{r}=0.44 ; \mathrm{p}<0.01$ ) groups. Figure 2 (Bland-Altman plot) indicates general agreement with the symmetric distribution of bias between the two groups studied. The mean absolute difference between estimated core and final infarct volume was similar in patients with and those without tandem lesions $(24 \pm 41 \mathrm{vs} .17 \pm 41$ $\mathrm{cm}^{3} ; \mathrm{p}=0.5$ ). A sensitivity analysis excluding patients with parenchymal hemorrhage did not alter the study findings.

\section{Discussion}

Our findings indicate that appropriate delay correction in CTP analysis allows for reliable ischemic core volume prediction among patients with ipsilateral extracranial steno-occlusive disease in AIS, where delay and dispersion effects may confound interpretation. 
Haussen et al.: Automated CT Perfusion for Ischemic Core Volume Prediction in

Fig. 1. Scatterplot indicating the correlation between baseline CTP $\mathrm{rCBF}$ ischemic core and final infarct volume. The line indicates the line of unity. rCBF = Relative CBF. a Tandem occlusion group. b Nontandem occlusion group.

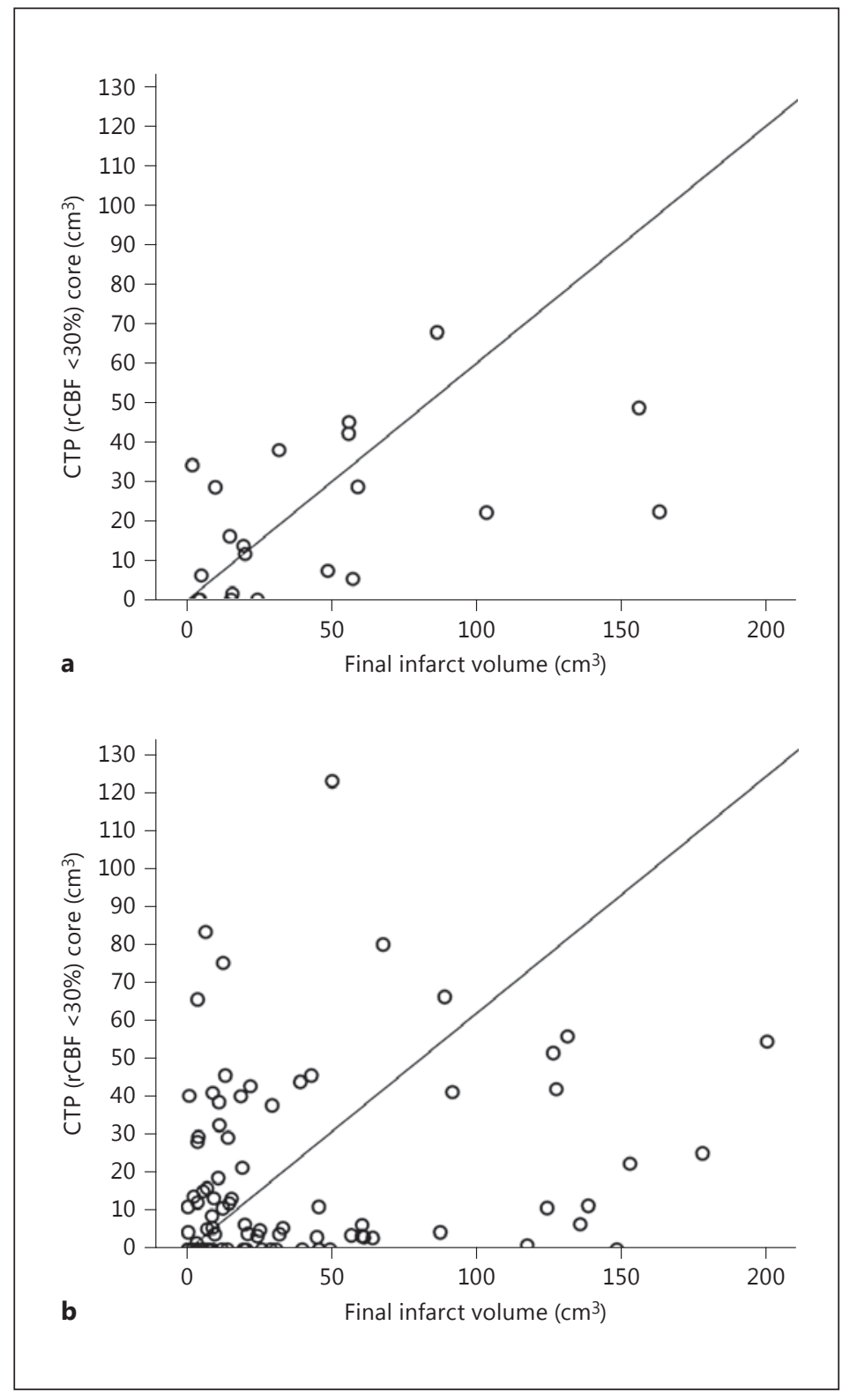

The accurate quantification of $\mathrm{CBF}$ and $\mathrm{T}_{\max }$ relies upon robust detection of an arterial input function (AIF), commonly selected for deconvolution from the brain-tissue timeattenuation course, for isolation of a theoretical tissue impulse response from which parametric maps may be computed. This operation partly corrects brain enhancement dynamics for bolus shape and other proximal factors, but may remain vulnerable to delay and dispersion effects related to hemodynamic disturbance thereafter. The potential impact of such factors has previously been broadly expounded; however, while a relative immunity of some analytic approaches was shown in simulation, investigation in the clinical setting remains unestablished. Given the potential influence upon perfusion quantitation by factors including the presence of underlying extracranial carotid steno-occlusive disease and the vessel targeted for AIF, we undertook a systematic study of performance among such patients $[15,16]$. RAPID utilizes an automated AIF algorithm which while optimized for 
Haussen et al.: Automated CT Perfusion for Ischemic Core Volume Prediction in

Fig. 2. Bland-Altman plot indicating agreement between baseline CTP rCBF ischemic core and final infarct volume. $\mathrm{rCBF}=$ Relative CBF. a Tandem occlusion group. b Nontandem occlusion group.

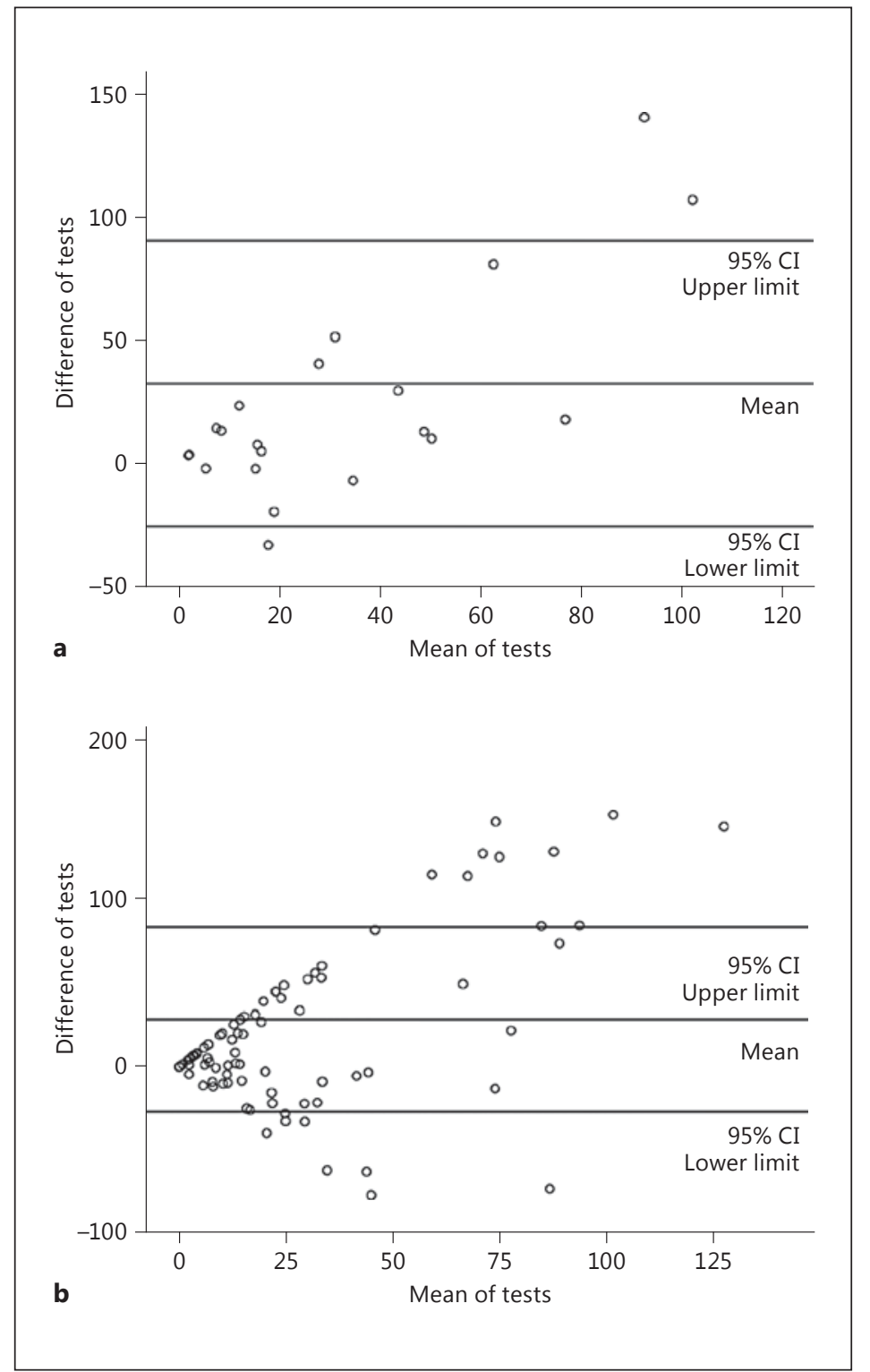

detection of candidate voxels and delay corrected, is uninformed specifically with regard to underlying proximal large-vessel steno-occlusive lesions. Our results would suggest robust estimations of infarction volumes irrespective of tandem lesions, where bolus dispersion and delay could engender errors such as flow underestimation or $\mathrm{T}_{\max }$ overestimation [8, 10].

RAPID CTP was recently demonstrated to provide accurate prediction of cores and tissues at risk in large-vessel AIS [6]. Compared with the recently published SWIFT-PRIME trial experience, the median core in our series was larger, which may be explained by the fact that our cohort was treated later after last-known-normal (median 333 vs. $150 \mathrm{~min}$ ) and had a higher median NIHSS score (19 vs. 17). However, our real practice experience compares very favorably with the SWIFT PRIME results; in fully reperfused (mTICI3) patients, the median difference between predicted core and final infarct volume was $11.0 \mathrm{~cm}^{3}$ in the SWIFT-PRIME trial compared to an overall median of $8 \mathrm{~cm}^{3}$ in our series. 
This study is limited by its retrospective design. While differences in $\mathrm{T}_{\max }$ and mismatch profiles were not detected between groups, validation of the accuracy of the perfusion parametric maps was focused primarily upon predictions of ischemic core volumes in this cohort of fully reperfused patients. Although simulation and phantom studies suggest that such delay-corrected approaches provide strong correlations in $\mathrm{T}_{\max }$ despite positive/negative temporal shifts, further investigation in untreated/nonreperfused subjects could better underscore the accuracy of total hypoperfused volume values and mismatch profiles in patients with tandem disease. A subgroup of patients had estimated CTP-derived baseline ischemic cores larger than the final infarct size, and this may be related to occasional RAPID ischemic core overestimation [17]. Another limitation is our pragmatic approach, which did not include a validation study with coregistration and per-voxel analysis.

\section{Conclusion}

The prediction of baseline ischemic core volume through an optimized CTP analysis employing rigorous normalization, thresholding, and voxel-wise analysis is not significantly influenced by the presence of underlying extracranial carotid steno-occlusive disease in large vessel AIS.

\section{Disclosure Statement}

The authors have no conflicts of interest to declare.

\section{References}

1 Berkhemer OA, Fransen PS, Beumer D, et al; MR CLEAN Investigators: A randomized trial of intraarterial treatment for acute ischemic stroke. N Engl J Med 2015;372:11-20.

2 Campbell BC, Mitchell PJ, Kleinig TJ, et al; EXTEND-IA Investigators: Endovascular therapy for ischemic stroke with perfusion-imaging selection. N Engl J Med 2015;372:1009-1018.

3 Jovin TG, Chamorro A, Cobo E, et al; REVASCAT Trial Investigators: Thrombectomy within 8 hours after symptom onset in ischemic stroke. N Engl J Med 2015;372:2296-2306.

4 Goyal M, Demchuk AM, Menon BK, et al; ESCAPE Trial Investigators: Randomized assessment of rapid endovascular treatment of ischemic stroke. N Engl J Med 2015;372:1019-1030.

5 Saver JL, Goyal M, Bonafe A, Diener HC, Levy EI, Pereira VM, Albers GW, Cognard C, Cohen DJ, Hacke W, Jansen O, Jovin TG, Mattle HP, Nogueira RG, Siddiqui AH, Yavagal DR, Baxter BW, Devlin TG, Lopes DK, Reddy VK, du Mesnil de Rochemont R, Singer OC, Jahan R; SWIFT PRIME Investigators: Stent-retriever thrombectomy after intravenous t-PA vs t-PA alone in stroke. N Engl J Med 2015;372:2285-2295.

6 Campbell BC, Yassi N, Ma H, Sharma G, Salinas S, Churilov L, Meretoja A, Parsons MW, Desmond PM, Lansberg MG, Donnan GA, Davis SM: Imaging selection in ischemic stroke: feasibility of automated CT-perfusion analysis. Int J Stroke 2015;10:51-54.

7 Albers GW, Goyal M, Jahan R, Bonafe A, Diener HC, Levy EI, Pereira VM, Cognard C, Cohen DJ, Hacke W, Jansen O, Jovin TG, Mattle HP, Nogueira RG, Siddiqui AH, Yavagal DR, Baxter BW, Devlin TG, Lopes DK, Reddy VK, du Mesnil de Rochemont R, Singer OC, Bammer R, Saver JL: Ischemic core and hypoperfusion volumes predict infarct size in SWIFT PRIME. Ann Neurol 2016;79:76-89.

8 Calamante F, Christensen S, Desmond PM, Østergaard L, Davis SM, Connelly A: The physiological significance of the time-to-maximum (Tmax) parameter in perfusion MRI. Stroke 2010;41:1169-1174.

9 Sasaki M, Kudo K, Ogasawara K, Fujiwara S: Tracer delay-insensitive algorithm can improve reliability of CT perfusion imaging for cerebrovascular steno-occlusive disease: comparison with quantitative single-photon emission CT. AJNR Am J Neuroradiol 2009;30:188-193.

10 Kudo K, Sasaki M, Østergaard L, Christensen S, Uwano I, Suzuki M, Ogasawara K, Shirato H, Ogawa A: Susceptibility of $T_{\max }$ to tracer delay on perfusion analysis: quantitative evaluation of various deconvolution algorithms using digital phantoms. J Cereb Blood Flow Metab 2011;31:908-912. 
11 Kudo K, Christensen S, Sasaki M, Østergaard L, Shirato H, Ogasawara K, Wintermark M, Warach S; Stroke Imaging Repository (STIR) Investigators: Accuracy and reliability assessment of CT and MR perfusion analysis software using a digital phantom. Radiology 2013;267:201-211.

12 Zaidat 00, Yoo AJ, Khatri P, et al; Cerebral Angiographic Revascularization Grading (CARG) Collaborators; STIR Revascularization Working Group; STIR Thrombolysis in Cerebral Infarction (TICI) Task Force: Recommendations on angiographic revascularization grading standards for acute ischemic stroke: a consensus statement. Stroke 2013;44:2650-2663.

13 Dehkharghani S, Bammer R, Straka M, Albin LS, Kass-Hout O, Allen JW, Rangaraju S, Qiu D, Winningham MJ, Nahab F: Performance and predictive value of a user-independent platform for CT perfusion analysis: threshold-derived automated systems outperform examiner-driven approaches in outcome prediction of acute ischemic stroke. AJNR Am J Neuroradiol 2015;36:1419-1425.

14 Fox AJ, Eliasziw M, Rothwell PM, Schmidt MH, Warlow CP, Barnett HJ: Identification, prognosis, and management of patients with carotid artery near occlusion. AJNR Am J Neuroradiol 2005;26:2086-2094.

15 Chiu FY, Teng MM, Kao YH, Chen YD, Luo CB, Chang FC, Guo WY, Chang CY: Selection of arterial input function for postprocessing of cerebral CT perfusion in chronic unilateral high-grade stenosis or occlusion of the carotid or middle cerebral artery. Acad Radiol 2012;19:8-16.

16 Araki Y, Mori S, Kanoh M, Kawai R, Mitomo M: Cerebral peak time mapping uniformity of the value of peak time. Neuroradiology 1987;29:160-162.

17 Boned S, Tomasello A, Padroni M, Coscojuela P, Cabero J, Rodriguez-Luna D, Pagola J, Muchada M, Rubiera M, Sanjuan E, Juega JM, Molina C, Ribó M: Ultra early CT-perfusion may overestimate initial infarct core. The ghost infarct core concept (abstract). Stroke 2016;47:A58. 